\title{
Policy Suggestions to Improve Living Conditions of Small Islands with Fewer than 10 Residents
}

\author{
PARK, Sung-Hyun (corresponding author) \\ Institution for Marine and Island Cultures, Mokpo National \\ University \\ sunghyun7908@gmail.com
}

\author{
LEE, Gyeong-A \\ Institution for Marine and Island Cultures, Mokpo National \\ University
}

Publication Information:

Received 7 April 2019, Accepted 17 May 2019, Available online 1 June 2019

DOI: 10.21463/jmic.2019.08.1.05

\section{Abstract}

By the end of 2017, there were 3,346 islands in Korea, a total that can be broken down into 470 inhabited islands and 2,876 uninhabited islands. It is expected that Korean islands will face the issue of ongoing island depopulation, due to a low birth rate and accelerated aging of the population. In particular, this study focuses on islands with fewer than 10 residents. Such islands face this problem more seriously than other islands. The Island Development Promotion Act, basis of the comprehensive policy on islands, in principle, targets islands with 10 or more people. Thus, there is no policy to support islands with fewer than 10 residents. Accordingly, this research examines the current situations and issues faced by islands with fewer than 10 residents that are now blind spots in the Korean government's policies towards island management. Within this context, the study offers some policy ideas for improvement. The analysis in this research proves that the most urgent problem to be solved for islands with fewer than 10 residents is access to the mainland. Next, to improve the living environment of residents, the government should provide them with conditions to meet basic needs such as the supply of drinking water, residency, power supply, and medical services, among other things.

\section{Keywords}

Korean island policy, Small Islands with Fewer than 10 Residents, Living Condition, DEMATEL, Distinction of island population 


\title{
Introduction
}

Article 3 of the Korean Constitution stipulates that, "the territory of the Republic of Korea is the Korean peninsula and its affiliated islands." As Korea is located on a peninsula with three coasts, islands are important parts of the nation. They are home to local residents and tourist destinations for people living elsewhere. Furthermore, the islands take up very important positions in the aspect of national defense.

As of end of 2017, there are 3,346 islands belonging to the territory of ROK, and 470 (14.1\%) of them are inhabited by people while the remaining $2,876(85.9 \%)$ do not have any permanent residents. The total number of people residing on islands is 851,172 , which take up $1.63 \%$ of the Korean population (Ministry of the Interior and Safety, 2018). Due to their small numbers, island residents have been marginalized when policies for development are conceived. The residents' satisfaction with quality of life, as a result, is lower than that of inland people (Korea Research Institute for Local Administration, 2015). With the aging of island residents and the fall in the number of resident population, it is expected that, by 2066, 63 (13.4\%) currently inhabited islands will become vacant, and the number of residents will be reduced by $33.8 \%$, with the proportion of residents over 65 being 32.5\% (Lee et al., 2016: 84). With the change in the ratio of inhabited islands to uninhabited ones, increasingly larger offshore areas will become blind spots in territorial management by the government.

The problem is that the current island policy in Korea excludes islands with fewer than 10 residents. That is, the Island Development Promotion Act, which is the basis of a comprehensive policy on islands, in principle, targets islands with 10 or more residents, leaving a policy vacuum for islands with fewer than 10 residents.

Accordingly, this research examines the current situations and issues faced by islands with fewer than 10 residents that are now blind spots in the Korean government's policies towards island management, and offers some policy ideas for improvement. In line with these research objectives, this article consists of the following parts. First, a theoretical background is given, summarizing the system of Korean island policies and the scope of policy support, and examining what problems could occur when an island loses all its inhabitants. Second, an analysis is presented of a survey that had been conducted on residents living on islands with fewer than 10 residents. The residents were surveyed by telephone interview and a questionnaire. Also, a DEMATEL survey was carried out among representative island residents from February to March 2019. Finally, based on the survey results, some policy ideas are formulated.

\section{Theoretical discussion}

\author{
Island policy system
}

Currently, the Korean government offers a diverse array of support policies, with different ministries dealing with islands depending on the topic at hand. The development and management of inhabited islands is handled by the Ministry of the Interior and Safety, under the Island Development Promotion Act. The development and management of uninhabited 
islands is handled by the Ministry of Oceans and Fisheries, under the Act on the Conservation and Management of Uninhabited Islands.

The government has separate support systems on islands located in specific geographic areas. The protection and support for the residents of the five islands off the West Sea are offered by the Ministry of the Interior and Safety, under the Special Act on Support for Five Islands of the Republic of Korea in the Yellow Sea. Protection and administration of Dokdo island and its surrounding areas is handled by the Ministry of Oceans and Fisheries, under the Act on the Sustainable Use of Dokdo. And, to protect marine environment of specific (i.e., uninhabited) islands, there is the Special Act on the Preservation of the Ecosystem in Island Areas including Dokdo. Meanwhile, if an island is designated as an economic growth promotion area, it becomes eligible for receiving financial support from the Ministry of Trade, Industry and Energy under the Special Act on Balanced National Development.

Table 1. Relevant Island Laws of Korea

\begin{tabular}{|c|c|c|c|}
\hline & & Government Department & Laws (enactment year) \\
\hline \multicolumn{2}{|c|}{ Inhabited islands } & $\begin{array}{l}\text { Ministry of the Interior and } \\
\text { Safety }\end{array}$ & ISLAND DEVELOPMENT PROMOTION ACT (1986) \\
\hline \multicolumn{2}{|c|}{ Uninhabited islands } & $\begin{array}{l}\text { Ministry of Oceans and } \\
\text { Fisheries }\end{array}$ & ACT ON THE CONSERVATION AND MANAGEMENT OF UNINHABITED ISLANDS (2007) \\
\hline \multirow[t]{3}{*}{$\begin{array}{l}\text { Specific island } \\
\text { region }\end{array}$} & \multirow[t]{2}{*}{ Security } & $\begin{array}{l}\text { Ministry of the Interior and } \\
\text { Safety }\end{array}$ & $\begin{array}{l}\text { SPECIAL ACT ON SUPPORT FOR FIVE ISLANDS OF THE REPUBLIC OF KOREA IN THE } \\
\text { YELLOW SEA (2010) }\end{array}$ \\
\hline & & $\begin{array}{l}\text { Ministry of Oceans and } \\
\text { Fisheries }\end{array}$ & ACT ON THE SUSTAINABLE USE OF DOKDO (2005) \\
\hline & Environment & Ministry of Environment & $\begin{array}{l}\text { SPECIAL ACT ON THE PRESERVATION OF THE ECOSYSTEM IN ISLAND AREAS } \\
\text { INCLUDING DOKDO (1997) }\end{array}$ \\
\hline
\end{tabular}

Source: Park(2017), Park(2015)

\section{The scope of islands supported by the government}

The scope by which different ministries manage and support islands can overlap, and it can happen that an island is not covered by any ministry. Among inhabited islands, if an island is classified as a growth promotion area, it is managed by the Ministry of Land, Infrastructure, and Transport. If it is an island located in a specific area, it is managed by the Ministry of the Interior and Safety. Currently, of the 371 islands that fall under the Islands Development Promotion Act, 185 islands are classified as being located in a specific area requiring special management, and 186 as growth promotion areas. In the case of uninhabited islands, while the Ministry of Oceans and Fisheries calls them uninhabited islands, the Ministry of Environment does categorize them separately. These islands are managed by different ministries depending on their respective characteristics.

This research started with the realization that there are some islands that are not covered by any of the governmental ministries. That is, the islands supported by the Ministry of the Interior and Safety are those surrounded by seas at high tide, under the Islands Development Promotion Act. But, Jeju island and the islands which have been connected to the 
mainland by a breakwater or bridge over 10 years ago are not defined as islands. In addition, those with fewer than 10 residents are in principle excluded as target areas for development, and as a result, they end up becoming blind spots in governmental support policies. This research focused on these small islands with fewer than 10 residents.

\section{Issues faced by islands when they become uninhabited}

A fall in the resident population of an island has wide implications. The offshore areas that are regularly used become smaller, which leads to them being monitored less frequently and becoming a blind spot in the government's management policy. It is difficult to monitor the areas for illegal activities that may take place. At the same time, it is difficult to respond quickly to offshore accidents in the areas, which increases the likelihood of injury or property damage. Many people worry that fewer people in these areas can reduce the use of those areas. Marine areas are working places for fishermen, and places of fish farming. Currently, the areas mainly used for such purposes are those surrounding inhabited islands. But, if islands continue to become uninhabited, and the number of people using the marine areas keeps decreasing, marine areas will also continue to become emptier. Thus, we need to have a solution to this problem.

\section{Analysis of the current situation of islands with fewer than 10 residents}

\section{Investigation into actual conditions}

As of February 2019, the number of islands with fewer than 10 residents is 34 . In a survey conducted by the Korean Local Administration Research Institute in 2016, it was found that there were 47 such islands. The recent investigation found that 13 islands has become uninhabited, and the number has become 34 . As 10 out of 34 islands are getting policy supports by being grouped with bigger islands. Thus, the number of islands treated in this research is 24 . To investigate current conditions of such islands, this research conducted telephone interviews with the representatives of those 24 islands from February 10 to 23, 2019. 


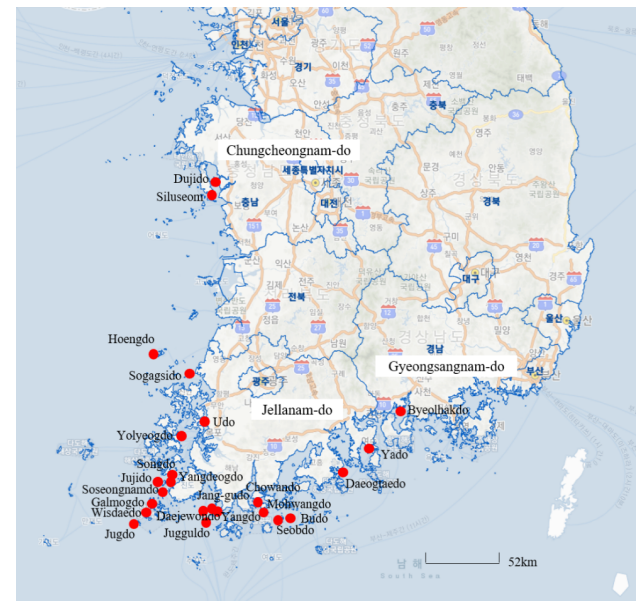

Fig 1. Surveyed islands

First, in terms of regional distribution, 21 islands (88\%) are located in South Jeolla province, 2 in South Chungcheong province, and one in south Gyeongsang province. Among the islands located in South Jeolla province, many are located in Wando gun (38\%) and Jindo gun (33\%), followed by Yeonggwang gun, Goheung gun, Shinan gun, and Yeosu si in descending order. Currently, 59 people live on these 24 islands, remotely from one another. Of these 59 people, 39 of them are male, and the remaining 20 are female. When looked at by age group those in their 60 s accounted for $39 \%$, which is the largest share. When those in their $70 \mathrm{~s}$ or $80 \mathrm{~s}$ are counted together with those in their $60 \mathrm{~s}$, the share of the elderly population over 60 years amounts to $67 \%$, which is very high.

Next, to understand the living conditions of those islands, the following was investigated: water supply (drinking water/underground water), power supply and medical care, selling of daily necessities, educational facilities, and existence of landing place, and so on. Living conditions of those islands were found to be poor. In particular, the lack of landing places, or the dilapidation of existing ones makes it very difficult for residents to access the main land. Actually, 8 islands lack landing places, making it difficult for coastal passenger ships to disembark. Electricity and running water, some of the most important utilities in the daily life of residents, are not well provided, as well. Only $39 \%$ of places is supplied with electricity by Korea Electric Power Corp.; other residents use electricity from generators or solar panels. Only $17 \%$ of residents use public water supply, and the rest use underground water or wells. As described above, residents of islands with fewer than 10 residents lack basic infrastructure for basic life conditions. 
Table 2. The Living Conditions of those Islands

\begin{tabular}{|c|c|c|c|c|c|c|c|c|c|c|}
\hline \multirow{2}{*}{ Province } & \multirow{2}{*}{ City } & \multirow{2}{*}{ Island } & \multicolumn{8}{|c|}{ Living Conditions } \\
\hline & & & $\begin{array}{l}\text { Water } \\
\text { Supply }\end{array}$ & $\begin{array}{l}\text { Power } \\
\text { Supply }\end{array}$ & $\begin{array}{l}\text { Medical } \\
\text { care }\end{array}$ & $\begin{array}{l}\text { Selling of daily } \\
\text { necessities }\end{array}$ & $\begin{array}{c}\text { Nursery } \\
\text { facilities }\end{array}$ & $\begin{array}{l}\text { Educational } \\
\text { facilities }\end{array}$ & $\begin{array}{l}\text { Street } \\
\text { light }\end{array}$ & $\begin{array}{l}\text { Ferry } \\
\text { boat }\end{array}$ \\
\hline Gyeongsangnam-do & Sacheon-si & Byeolhakdo & (1) & (a) & $x$ & $x$ & $x$ & $x$ & o & $x$ \\
\hline \multirow[t]{21}{*}{ Jeollanam-do } & Goheung-gun & Daeogtaedo & (2) & (a) & $x$ & $x$ & $x$ & $x$ & o & o \\
\hline & Muan-gun & Udo & (2) & (a) & $x$ & $x$ & $x$ & $x$ & $\mathrm{x}$ & $\mathrm{x}$ \\
\hline & Sinan-gun & Yolyeogdo & (1) & (b) & $x$ & $x$ & $x$ & $x$ & $x$ & $\mathrm{x}$ \\
\hline & Yeosu-si & Yado & (4) & (a) & $x$ & $x$ & $x$ & $x$ & 0 & 0 \\
\hline & \multirow{2}{*}{$\begin{array}{l}\text { Yeonggwang- } \\
\text { gun }\end{array}$} & Sogagsido & (3) & (c) & $x$ & $x$ & $x$ & $x$ & o & o \\
\hline & & Hoengdo & (3) & (a) & $x$ & $\mathrm{x}$ & $x$ & $x$ & 0 & $x$ \\
\hline & \multirow[t]{8}{*}{ Wando-gun } & Mohwangdo & (1) & (c) & $x$ & $x$ & $x$ & $x$ & $x$ & o \\
\hline & & Yangdo & (2) & (b) & $x$ & $x$ & $x$ & $x$ & $\mathrm{x}$ & 0 \\
\hline & & Jugguldo & (3) & (b) & $x$ & $x$ & $x$ & $x$ & o & o \\
\hline & & Chowando & (1) & (a) & $x$ & $x$ & $x$ & $x$ & $x$ & 0 \\
\hline & & Seobdo & (1) & (b) & $x$ & $x$ & $x$ & $x$ & o & o \\
\hline & & Budo & (1) & (c) & $x$ & $x$ & $x$ & $x$ & $x$ & o \\
\hline & & Daejewondo & (3) & (b) & $x$ & $x$ & $x$ & $x$ & $x$ & o \\
\hline & & Jang-gudo & (2) & (a) & $x$ & $x$ & $x$ & $x$ & $x$ & $x$ \\
\hline & \multirow[t]{7}{*}{ Jindo-gun } & Galmogdo & (3) & (a) & $x$ & $x$ & $x$ & $x$ & $x$ & o \\
\hline & & Soseongnamdo & (3) & (a) & $x$ & $x$ & $x$ & $x$ & o & o \\
\hline & & Songdo & (3) & (b) & $x$ & $x$ & $x$ & $x$ & $x$ & o \\
\hline & & Yangdeogdo & (3) & (b) & $x$ & $x$ & $x$ & $x$ & $x$ & o \\
\hline & & Jujido & (3) & (b) & $x$ & $x$ & $x$ & $x$ & $x$ & 0 \\
\hline & & Jugdo & (3) & (b) & $x$ & $x$ & $x$ & $x$ & $x$ & $x$ \\
\hline & & Wisdaedo & (3) & (a) & $x$ & $x$ & $x$ & $x$ & $x$ & $x$ \\
\hline \multirow[t]{2}{*}{ Chungcheongnam-do } & Boryeong-si & Siluseom & (1) & (b) & $x$ & $\mathrm{x}$ & $x$ & $x$ & o & o \\
\hline & Taean-gun & Dujido & (4) & (a) & $x$ & $x$ & $x$ & $x$ & o & 0 \\
\hline
\end{tabular}

Legend: Water Supply: (1) Underground water, (2) Rain water, (3) Water boat, (4) Simplified wide area water supply. Power Supply: (a) Korea electric power, b Sunlight generation, (c) House power plant.

The major industry of the investigated small islands is fishery. The proportion of households whose only source of income is fishery is $46 \%$. Ten percent of households do both farming and fishery, and $8 \%$ combines fishery and tourism business. The remaining small numbers of people either work in agriculture (5\%), or tourism such as management of 
vacation houses or condos (3\%). Fifteen percent of residents do not have any income, making it likely that poverty is also a serious problem on small islands.

\section{Survey on residents' perception}

After telephone interviews, a face-to-face survey on residents was conducted from March 1 to 15,2019 . As it was problematic to visit all the 24 islands and conduct a survey, this research chose 11 islands as samples, and had a faceto-face survey with residents (survey on residents' perception and DEMATEL survey). The respondents were selected using a purposeful sampling method. One respondent for each of the 11 islands participated in the response. They were those who could represent opinions of the population, although they wrote down their own responses to the questions.

First, in response to the question on life satisfaction, 6 respondents (55\%) said they were unsatisfied. Only 1 respondent (9\%) answered being satisfied. As the biggest problem of the island, 4 respondents (36.4\%) mentioned the problem of inconvenient access, followed by population aging (18.2\%), and the poor living environment $(18.2 \%)$.

Among the problems regarding living environment, 5 respondents (45.5\%) pointed out the problem of drinking water, followed by issues related to the need for improved housing and repair of village roads. Also reported were transport and residential areas. Five respondents (45.5\%) noted the means of marine transport, followed by pavement of village roads (27.3\%). Among problems regarding the mooring system of fishing boats, 7 respondents $(63.6 \%)$ answered that landing places should be built. In terms of social and medical care, 3 respondents $(27.3 \%)$ wished that medical and public health facilities were improved.

In terms of source of income, $46 \%$ of families generate income through fishery. In response to the questions asking them what businesses are promising in the future, $27.3 \%$ pointed out fish farming business, and $27.3 \%$ service jobs in tourism. To make people continue to live in such islands, they need to be economically independent. Thus, there should be a way to generate income for them by improving fishery environment.

\section{Structural approach to policy issues}

\section{Survey design}

What are the factors undermining the living conditions of island residents? Borrowing the procedure of Park (2016) who extracted objective factors through analysis of previous researches and test of specialists, this research set the analytical indices. Considering the population and area characteristics of islands with fewer than 10 residents, this research extracted the following g factors: aging population, welfare facilities, industrial structure, labor force, income source, access to mainland, lodging and leisure facilities, and living conditions. 
Table 3. Derivation of problem elements in the Improvement of Settlement Conditions on island areas

\begin{tabular}{|c|c|c|c|c|c|c|c|c|c|c|c|c|c|}
\hline Problems & $\begin{array}{l}\text { Sim, } \\
2013\end{array}$ & $\begin{array}{l}\text { Oh, } \\
2009\end{array}$ & $\begin{array}{l}\text { Lee, } \\
2008\end{array}$ & $\begin{array}{l}\text { Kim, } \\
2012\end{array}$ & $\begin{array}{l}\text { Kim, } \\
2005\end{array}$ & $\begin{array}{l}\text { Park, } \\
2002\end{array}$ & $\begin{array}{l}\text { Yoon, } \\
2000\end{array}$ & $\begin{array}{l}\text { Kim, } \\
2002\end{array}$ & $\begin{array}{l}\text { Shin, } \\
1995\end{array}$ & $\begin{array}{l}\text { Uhm, } \\
1997\end{array}$ & $\begin{array}{l}\text { Son, } \\
2003\end{array}$ & $\begin{array}{l}\text { Go, } \\
2008\end{array}$ & $\begin{array}{l}\text { Kim, } \\
2006\end{array}$ \\
\hline C1. Serous again society & & & - & & & & & & - & & - & - & - \\
\hline $\begin{array}{l}\text { C2. Shortage of residential welfare } \\
\text { facilities }\end{array}$ & - & - & - & $\bullet$ & - & & & - & & & & & \\
\hline C3.Fragmented industrial structure & & & - & & & - & & & - & - & & - & \\
\hline C4. Limited labor sources & & & & & & & & & & - & & - & \\
\hline C5. Decreasing income sources & & & & & & & & & - & - & - & & \\
\hline $\begin{array}{l}\text { C6. Underdeveloped public } \\
\text { transportation to the mainland }\end{array}$ & - & & - & - & - & - & - & & - & & & & - \\
\hline $\begin{array}{l}\text { C7. Lack of accommodation and } \\
\text { leisure facilities }\end{array}$ & & & & & & & & & & & & & - \\
\hline C8. Poor residential environment & - & & - & • & - & & & - & - & • & & & \\
\hline
\end{tabular}

A data matrix for the DEMATEL was prepared to analyze the relationship between the various problematic elements associated with the Improvement of living Conditions on island areas (Park, 2016). DEMATEL investigates targets that are closely related to the issues. Questionnaire surveys with a matrix sheet were conducted to analyze the data and determine the relationships between eight elements ( $\mathrm{C} 1-\mathrm{C} 8)$. The row of the matrix shows "cause" and the column shows "effect." The survey question asked the extent to which each element influences the others. The respondents were scored on a five-point scale $(0,1,2,3$, and 4$)$ on the pairwise comparison matrix (0: No influence, 1: Low influence, 2: Medium influence, 3: High influence, 4: Very high influence) (Jang et al, 2017; Park, 2016). 
Table 4. Analysis Process and Methodology of DEMATEL

\begin{tabular}{|c|c|c|}
\hline Step & Methodology & Formula \\
\hline $\begin{array}{l}\text { 1. Calculation the direct- } \\
\text { influence matrix using } \\
\text { scores }\end{array}$ & - To obtain $n \times n$ matrix A from the expert's questionnaire & $A=\left[\begin{array}{ccc}a_{11} & \cdots & a_{1 n} \\
\vdots & \ddots & \vdots \\
a_{n 1} & \cdots & a_{n n}\end{array}\right]$ \\
\hline $\begin{array}{l}\text { 2. Normalizing the } \\
\text { direct-influence } \\
\text { matrix }(X)\end{array}$ & $\begin{array}{l}\text { - Generalization: to obtain the average matrix by averaging all the } \\
\text { experts' scores } \\
\text { - Normalization Matrix }(\mathrm{X}) \text { : to seek the sum of each row and } \\
\text { normalize it after dividing the sum of the rows by the largest } \\
\text { value }\end{array}$ & $\begin{array}{c}X=\frac{1}{\max \sum_{i=1}^{n} a_{i j}} \bullet A \\
\quad i, j=1,2, \ldots, n\end{array}$ \\
\hline $\begin{array}{l}\text { 3. Attaining the total- } \\
\text { relationship matrix(T) }\end{array}$ & $\begin{array}{l}\text { - The total-relationship matrix }(T) \text { indicates only direct relations } \\
\text { - A continuous decrease of the indirect effects of issues along } \\
\text { with the powers of matrix } X \text { guarantees convergent solutions to } \\
\text { the matrix inversion }\end{array}$ & $\begin{array}{c}T=X+X^{2}+\cdots X^{m}=X(I-X)^{-1} \\
T=\left[t_{i j}\right]_{n \times n}, i, j=1,2, \cdots, n\end{array}$ \\
\hline 4. Analyzing the results & $\begin{array}{l}\text { - The sum of rows }(D) \text { for the total-relationship matrix }(T) \text { indicates } \\
\text { the degree of effect or cause for each issue in the whole problem } \\
\text { - The sum of columns }(R) \text { is the reverse-effect degree or degree of } \\
\text { cause for related problems through the collection of all problems }\end{array}$ & $\begin{array}{l}D=\left[\sum_{i=1}^{n} t_{i j}\right]_{n \times 1}=\left[t_{i}\right]_{n \times 1} \\
R=\left[\sum_{j=1}^{n} t_{i j}\right]_{1 \times n}=\left[t_{j}\right]_{n \times 1}\end{array}$ \\
\hline
\end{tabular}

Jang et al, 2017; Park, 2016.

The sum of rows (D) in the Total-relation Matrix ( $T$ ) indicates influence, or the extent of causation on the overall problems accounted for by each problem. The sum of columns (R), which indicates absence of influence, refers to the degree of causation on the relevant problem assessed by amassing the overall problems. Here, $D+R$ (centrality) denotes the importance of a relevant problem within the overall problems regardless of cause and effect. On the other hand, D-R (causation) becomes the indicator used to exhibit whether a problem constitutes the cause or effect when measured against the overall problems. In other words, $D-R>0$ denotes a strong character as a dispatcher while $D-R<0$ indicates a strong character as a receiver (Table 5). The structure of complex causal relationships based on influence and cause is best visualized using a directed graph (Park, 2016).

\section{Analytic results}

First, row total (D) indicating the degrees of cause shows that the factors undermining settlement in islands with fewer than 10 residents are as follows: inconvenient transport to mainland $(C 6,9.524)$ is the most important cause, followed by poor housing environment $(C 8,9.261)$, and decreasing income source $(C 5,9.087)$. On the other hand, column total $(R)$ indicating the degrees of results shows that decreasing income source $(C 5,10.636)$ is the most important finding, followed by inconvenient transport to mainland $(\mathrm{C} 6,9.673)$, and limited labor supply $(\mathrm{C} 4,8.942)$. 
Table 5. Result of DEMATEL

\begin{tabular}{|l|l|l|l|l|l|l|l|l|l|l|l|l|l|}
\hline & \multicolumn{9}{|c|}{ (1) Total-relationship Matrix } & \multicolumn{4}{c|}{ (2) Center and Cause } \\
\cline { 2 - 13 } & C1 & C2 & C3 & C4 & C5 & C6 & C7 & C8 & D & R & D+R & D-R \\
\hline C1 & 0.963 & 0.951 & 0.952 & 1.120 & 1.375 & 1.245 & 0.972 & 1.098 & 8.675 & 8.389 & 17.064 & 0.287 \\
\hline C2 & 0.966 & 0.769 & 0.844 & 1.040 & 1.227 & 1.126 & 0.892 & 1.009 & 7.873 & 7.386 & 15.259 & 0.487 \\
\hline C3 & 0.975 & 0.858 & 0.788 & 1.054 & 1.264 & 1.157 & 0.906 & 1.019 & 8.021 & 7.422 & 15.443 & 0.599 \\
\hline C4 & 1.074 & 0.920 & 0.955 & 1.016 & 1.366 & 1.216 & 0.933 & 1.094 & 8.574 & 8.942 & 17.516 & -0.368 \\
\hline C5 & 1.150 & 0.971 & 0.997 & 1.227 & 1.280 & 1.289 & 0.996 & 1.176 & 9.087 & 10.636 & 19.723 & -1.550 \\
\hline C6 & 1.167 & 1.038 & 1.051 & 1.256 & 1.498 & 1.217 & 1.064 & 1.234 & 9.524 & 9.673 & 19.196 & -0.149 \\
\hline C7 & 0.933 & 0.852 & 0.846 & 1.002 & 1.185 & 1.111 & 0.770 & 0.993 & 7.691 & 7.572 & 15.262 & 0.119 \\
\hline C8 & 1.161 & 1.029 & 0.989 & 1.228 & 1.442 & 1.311 & 1.038 & 1.064 & 9.261 & 8.686 & 17.948 & 0.575 \\
\hline
\end{tabular}

On the other hand, Figure 2 expresses coordinates of factors and directedness between items on the $X-Y$ coordinates with degree of centrality $(D+R)$ and degree of cause (D-R) as $X$ axis and $Y$ axis, respectively. Analysis showed that the centrality $(D+R)$ which is summation of degree of influence and degree of being influenced, suggests to be the most serious factor is decreasing income source $(\mathrm{C} 5,19.723)$, followed by inconvenient transport links to mainland (C6, 19.196). These are multi-faceted issues with numerous causes and implications.

Next, degree of causes indicating the difference between degree of influence and degree of being influenced revealed that the problematic factor which is a strong candidate of cause is fragmented industrial structure $(C 3,-0.599)$, and that the problematic factor which is a strong candidate for findings is income source $(C 5,-1.550)$.

When we combine degree of centrality $(D+R)$ and degree of cause $(D-R)$, we can find that the central problematic structure undermining living environment in islands with fewer than 10 residents is inconvenient access to mainland and decreasing income sources. Along with that, poor housing environment and accelerated aging of the population, and limited labor force also work as causes to reduce income sources. In conclusion, to improve living environment of such islands, we need strategies to improve access to mainland and create income sources. 


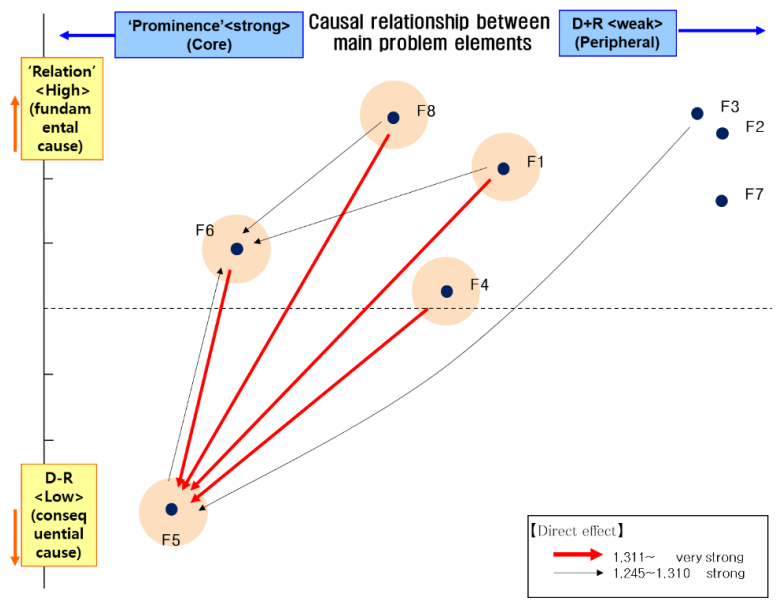

Fig 2. Causality diagram of criteria

\section{Policy suggestions}

It is expected that Korean islands will face the issue of ongoing decrease in the size of their population, due to a low birth rate and accelerated aging of the existing population. In particular, islands with fewer than 10 residents, targets of this research, face such a problem more seriously than other islands. We need to prepare conditions to live to Korean islands, because they are not only important as living spaces, but as the place to protect marine sovereignty of Korea.

The analysis in this research proves that the most urgent problem to be improved for islands with fewer than 10 residents is access to the mainland. To improve access, it is desirable to adopt a public management system for passenger ships. The system is what the central government or local government owns the management of not very profitable ships traveling lanes to remote islands. As passenger ships are the only transport means available to island residents and a very important element in living conditions and quality of life, those ships should be run regularly to islands that have only one resident. While the long-term goal should be public management of such transport modes, the short-term goal is to provide subsidy to private passenger companies to make them the ships to such remote islands.

Next, to improve the living environment of residents, the government should provide them with conditions to meet basic needs life such as drinking water, residency, power supply, and medical service, among other things. Specifically, the government should consider a project to support building facilities to store rainwater, the project to support repairing old houses, adoption of medical drone, and the project to build solar power generating facilities. In addition, to promote economic growth on such islands, it should actively promote the construction of mooring docks, resting area for fishers, and fish farming islands. Finally, the government should start a system to convert the islands with fewer than 10 residents as leisure spaces for Korean people. To make island residents those who can give benefits to inland people, rather than those who receive assistance from the government, the government can consider the followings: the project to activate lodging business, adoption of island tourism programs, and a project to encourage people to return to fishery and farming. 
It is necessary for the government to prepare institutional compensatory measures and systematic and comprehensive support systems to secure settlement safety and establishment and preservation of marine sovereignty of islands with fewer than 10 residents.

\section{Acknowledgements}

This paper was supported by the National Research Foundation of Korea Grant funded by the Korean Government (MEST) (NRF-2009-361-A00007).

\section{References}

Choi et al, 2017, A Study on the Utilization of Islands for the Effective Management of the Surrounding Seas, Korea Maritime Institute. (Korean) Go, Dukab, 2008, A Study on Possibilities of the Eco-Tourism Development by using of the Salterns: The Case of Shinan gun, Business Education Research21, 441-466.(Korean with English abstract).

Jang, M.Y., Park S.H \& Lee, M. H., 2017, Conservation Management of Historical Assets Through Community Involvement: A Case Study of Kanazawa Machiya in Japan, Journal of Asian Architecture and Building Engineering, 16(1), 53 60.

Kim, Hyoungseo., 2006, A Study on the Activation of the Marine Tourism in Shin an gun, Korea, The Tourism Sciences Society of Korea Conference, 32-82(Korean with English abstract).

Kim, Jimin, 2005, The Study on the Modeling Development of Dwelling House of Islands in the Future Based on the Insularity and the Factor of Traditional Culture, Journal of The Korean Housing Association. 16(5), 1-12.(Korean with English abstract).

Kim, Jun, 2012, The reflection on the Islands Development Policies and Alternatives for Sustainable Islands Making, ISLAND CULTURES. 40. (Korean with English abstract).

Kim, Nongoh, Lee, Dongshin, \& Rim, Dongoh, 2005, A Direction on the Development of Marine Tourism for the Development of Chonnam's Island, The Journal of Korean Island17(1), 427-456.(Korean with English abstract).

Lee et al, 2016, A Study on the Development Plan and Analysis of the population change of the island, Korea Research Institute Institute for Local Administration.(Korean)

Lee, Kyeyeol, Kim, Yeonsu, 2008, A Study on the Direction of Development on Islands Region: Centered on the Case of Eocheongdo,The Journal of Korean Island, 20(2), 53-70.(Korean with English abstract).

Oh, Seunghwan., 2009, A Study Determinants on the Sense of Community in Island Area, Journal of Community Welfare28, 1-20.(Korean with English abstract).

Park, Jaesun, 2002, The Policy Strategy and States for Islands Development of Jeonnam Province, The Journal of Korean Island, 14(1), 1-16. (Korean with English abstract).

Park, Sunghyun, 2016. A strategic approach to policy tasks for the development of Korea's island areas.J. Mar. Isl. Cult. 5, 14-21.

Shin, Soonho, 1995, Development Strategies for Depressed Island Area, Urban Information Service, 14(7), 5-8.(Korean with English abstract). 
Sim, SeungHee, 2013, The Changes of Islands Regions Driven by Island Policies in Korea Since Modern Times, The Journal of Korean Cultural and Historical Geographers, 25(1), 63-85. (Korean with English abstract).

Son, Hyeungsoeb, 2007, A Study of Survey on the Farm Liabilities in Jeonnam Region, Journal of Korean Regional Development, 6(2), 147-164. (Korean with English abstract).

Uhm, Gicheol, 1997, Strategy and Direction of Development on Islands Region, National Territory184, 40-51.(Korean with English abstract). Yon, Sangho, 2000, The Development planning on the island: in case of Deok Jeok island, Journal of the Korean Regional Development Association.12(2), 67-79.(Korean with English abstract). 